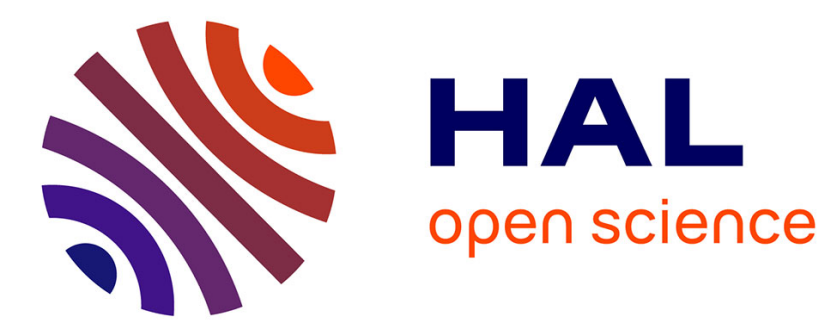

\title{
New Oriental genera in the family Issidae (Hemiptera: Fulgoromorpha)
}

\author{
Menglin Wang, Thierry Bourgoin, Yalin Zhang
}

\section{To cite this version:}

Menglin Wang, Thierry Bourgoin, Yalin Zhang. New Oriental genera in the family Issidae (Hemiptera:

Fulgoromorpha). Zootaxa, 2017, 4312 (2), pp.355-367. 10.11646/zootaxa.4312.2.10 . hal-01677387

\section{HAL Id: hal-01677387 \\ https://hal.sorbonne-universite.fr/hal-01677387}

Submitted on 8 Jan 2018

HAL is a multi-disciplinary open access archive for the deposit and dissemination of scientific research documents, whether they are published or not. The documents may come from teaching and research institutions in France or abroad, or from public or private research centers.
L'archive ouverte pluridisciplinaire HAL, est destinée au dépôt et à la diffusion de documents scientifiques de niveau recherche, publiés ou non, émanant des établissements d'enseignement et de recherche français ou étrangers, des laboratoires publics ou privés. 


\title{
New Oriental genera in the family Issidae (Hemiptera: Fulgoromorpha)
}

\author{
MENGLIN WANG ${ }^{1,2,3}$, THIERRY BOURGOIN ${ }^{2,4}$ \& YALIN ZHANG ${ }^{1,4}$ \\ ${ }^{1}$ Key Laboratory of Plant Protection Resources and Pest Management of the Ministry of Education, Entomological Museum, Nor- \\ thwest A\&F University, Yangling, Shaanxi, 712100, China \\ ${ }^{2}$ Institut de Systématique, Évolution, Biodiversité, ISYEB-UMR 7205 MNHN-CNRS-UPMC-EPHE, Muséum national d'Histoire \\ naturelle, Sorbonne Universités, 57 rue Cuvier, CP 50, F-75005 Paris, France \\ ${ }^{3}$ Key Laboratory of Southwest China Wildlife Resources Conservation of the Ministry of Education, China West Normal University, \\ Nanchong, Sichuan, 637009, China \\ ${ }^{4}$ Corresponding authors.E-mails: bourgoin@mnhn.fr; yalinzh@nwsuaf.edu.cn
}

\begin{abstract}
Three new Oriental Issidae genera and two new species identified by a previous molecular phylogeny analysis are described. Two new genera belong to the tribe Kodaianellini: Kodaianellissus gen. nov., type species: K. intorqueus sp. nov. from China and Tetricissus gen. nov., type species: T. philo (Fennah, 1978) from Vietnam. Another new genus representing Sarimini: Longieusarima gen. nov., type species: L. lunulia sp. nov. is described from China.
\end{abstract}

Key words: Hemiptera, Fulgoromorpha, Issidae, China, Vietnam

\section{Introduction}

The family Issidae (Hemiptera: Fulgoromorpha) is one of the largest planthopper families consisting of about one thousand species worldwide (Bourgoin, 2017). According to new molecular phylogeny analyses (Wang et al., 2016), this family was recently divided into three subfamilies and seven tribes: Thioniinae Melichar, 1906 (Thioniini Melichar, 1906), Issinae Spinola, 1839 (Issini Spinola, 1839 and Hysteropterini Melichar, 1906) and Hemisphaeriinae Melichar, 1906 (Kodaianellini Wang, Zhang et Bourgoin, 2016, Sarimini Wang, Zhang et Bourgoin, 2016, Parahiraciini Cheng et Yang, 1991, Hemisphaeriini Melichar, 1906). During these molecular phylogeny analyses, several genera in the Hemisphaeriinae sensu Wang et al., 2016, were revealed to be paraphyletic and in need of taxonomic revision. The purpose of this paper is to describe three of those new genera and two new species. The first two new genera belong to the tribe Kodaianellini: Kodaianellissus gen. nov. and Tetricissus gen. nov., and the third new genus belongs to Sarimini: Longieusarima gen. nov. Other undescribed taxa also revealed in these molecular phylogeny analyses will be described later.

\section{Material and methods}

The studied specimens belong to the Institute of Zoology, Chinese Academy of Sciences (IZCAS), Beijing, China and the Museum national d'Histoire naturelle (MNHN), Paris, France. Type specimens are deposited in MNHN or are temporarily deposited in Entomological Museum of Northwest A\&F University (NWAFU), Yangling, China.

The abdomen of each specimen was separated from the body, and boiled in a $10 \% \mathrm{NaOH}$ solution for 5 to 10 minutes until muscles were completely dissolved leaving tegumentary structures. After rinsing in distilled water for several times, terminalia were subsequently dissected. These structures were transferred to glycerin for final dissection and observation. Some genitalia were stained with permanent Black E Chlorazol stain. For some species, several drops of Barber's fluid on dry specimens allowed dissection of the hindwing without damaging the specimens, and wings were stored separately underneath the specimens. Photographs for external morphology and 
terminalia characters were taken using a Leica DFC camera attached to Leica M205A stereomicroscope and further refined with LAS V3.7 software. Terminology for wing venation follows Bourgoin et al. (2015), male terminalia follows Bourgoin (1987) and female terminalia follows Bourgoin (1993).

\section{Taxonomy}

Issidae Spinola, 1839

\section{Hemisphaeriinae Melichar, 1906}

\section{Kodaianellini Wang, Zhang et Bourgoin, 2016}

\section{Kodaianellissus gen. nov.}

Type species: Kodaianellissus intorqueus sp. nov., here designated.

Diagnosis. This genus is very similar to the genus Kodaianella Fennah, 1956 in general appearance, but differs by: 1) ScP-R-MP-Cu lobe of hindwing around 1.5 times wider than Pcu- $\mathrm{A}_{1}$ lobe (Fig. 6), but the latter much narrower, 4 times wider than Pcu-A $\mathrm{A}_{1}$ lobe (Gnezdilov, 2013, fig. 6); 2) The forewing, in lateral view, broadest at basal 1/3 (Fig. 2), but broadest from basal 1/3 to apex in Kodaianella (Gnezdilov, 2013, fig. 3); 3) Frons slightly narrower than in Kodaianella, frons just 1.3 times broader at widest part than long in midline, but 1.5 times in Kodaianella.

Description. Head with compound eyes almost as wide as thorax (Figs. 1, 3). Vertex rectangular, obviously broader than long, median carina present; anterior margin slightly convex, posterior margin strongly angular concave medially (Figs. 1, 3). Frons roundly widened below antenna, apical margin almost straight, apical and lateral margins carinate and elevated, median carina obviously elevated from apex extending to near base, but not reaching frontoclypeal sulcus (Fig. 4); frons with apical and lateral area distributed with numerous tubercles, tubercles change from small to large from apical to lateral part (Fig. 4). Frontoclypeal suture strongly convex (Fig. 4). Clypeus with several transverse thin stripes on lateral sides (Fig. 4). Rostrum short, reaching midcoxae. Gena in lateral view flattened and oblique, with small protuberance near base (Fig. 2). Pronotum triangular, with two small incisions on disc, median carina present (Figs. 1, 3). Mesonotum smooth, without carina (Figs. 1, 3). Forewings elongate, distinctly longer than wide, with very narrow hypocostal plate, longitudinal veins obvious and elevated, forewing slightly broadened near the basal $1 / 3$ (Figs. 1, 2, 5). Vein $\mathrm{ScP}+\mathrm{R}$ first separating near base, $\mathrm{ScP}+\mathrm{RA}$ vein extremely long, surpassing the apical $1 / 3$ of costal margin, the terminal of RP vein almost reaching the outer margin of forewing; MP vein first fork near the basal $1 / 4, \mathrm{MP}_{1+2}$ straight, fork again at apical $1 / 9, \mathrm{MP}_{3+4}$ sinuate, without fork; $\mathrm{CuA}$ vein first separate at apical 1/3; MP first fork before the first separation of CuA (Fig. 5). Clavus obvious, veins Pcu and $A_{1}$ fused at basal 1/2 of clavus (Fig. 5). Forewings with numerous transverse veins (Figs. 1, 2, 5). Hindwing well developed, 3-lobed; Pcu- $A_{1}$ lobe distinctly thinner than ScP-R-MP-Cu lobe; $A_{2}$ lobe narrow with anterior and posterior margins subparallel and distinctly surpassing half length of Pcu- $\mathrm{A}_{1}$ lobe; $\mathrm{A}_{2}$ not branched (Fig. 6). Hind tibia with 2 lateral spines on apical half.

Male terminalia. Anal tube in lateral view long and narrow (Fig. 7). Gonostyli triangular in profile, becoming broader from base to apex, caudo-ventral angle rounded, dorso-lateral margin with process; capitulum very long and narrow, with auricular process (Figs. 7, 9). Pygofer rectangular in lateral view, apparently longer than width, posterior margin not obviously caudally produced (Fig. 7). Periandrium symmetrical, basally tubular, apical part divided into dorso-lateral lobe and ventral lobe (Fig. 10). Dorso-lateral lobe longer than ventral lobe (Fig. 11). Aedeagus with pair of ventral processes directed dorso-basad.

Female terminalia. Anal tube relatively long in lateral view, reaching level of posterior margin of gonoplac. Anterior connective lamina of gonapophysis VIII with teeth at apex and outer lateral margin, inner lateral margin without teeth (Fig. 18). Gonocoxa VIII subquadrangular, connected to gonapophysis VIII with rectangular angle (Fig. 18). Gonapophysis IX in lateral view boat-shaped (Fig. 16). Gonoplac subrectangular in lateral view (Fig. 15), fused at middle near base, widest at base (Fig. 13). Hind margin of sternite VII concave medially (Fig. 17).

Etymology. The name of this new genus is an arbitrary combination between two generic names of issids: 
Kodaianella and Issus, indicating this genus has a close relationship with the genus Kodaianella. The gender is masculine.

Note. This genus refers to the taxon "gen. nov. apud Kodaianella" on the molecular phylogeny trees of Wang et al. (2016). The position of this genus within Kodaianellini is supported by both the molecular phylogenetic results and the morphological characters listed above.
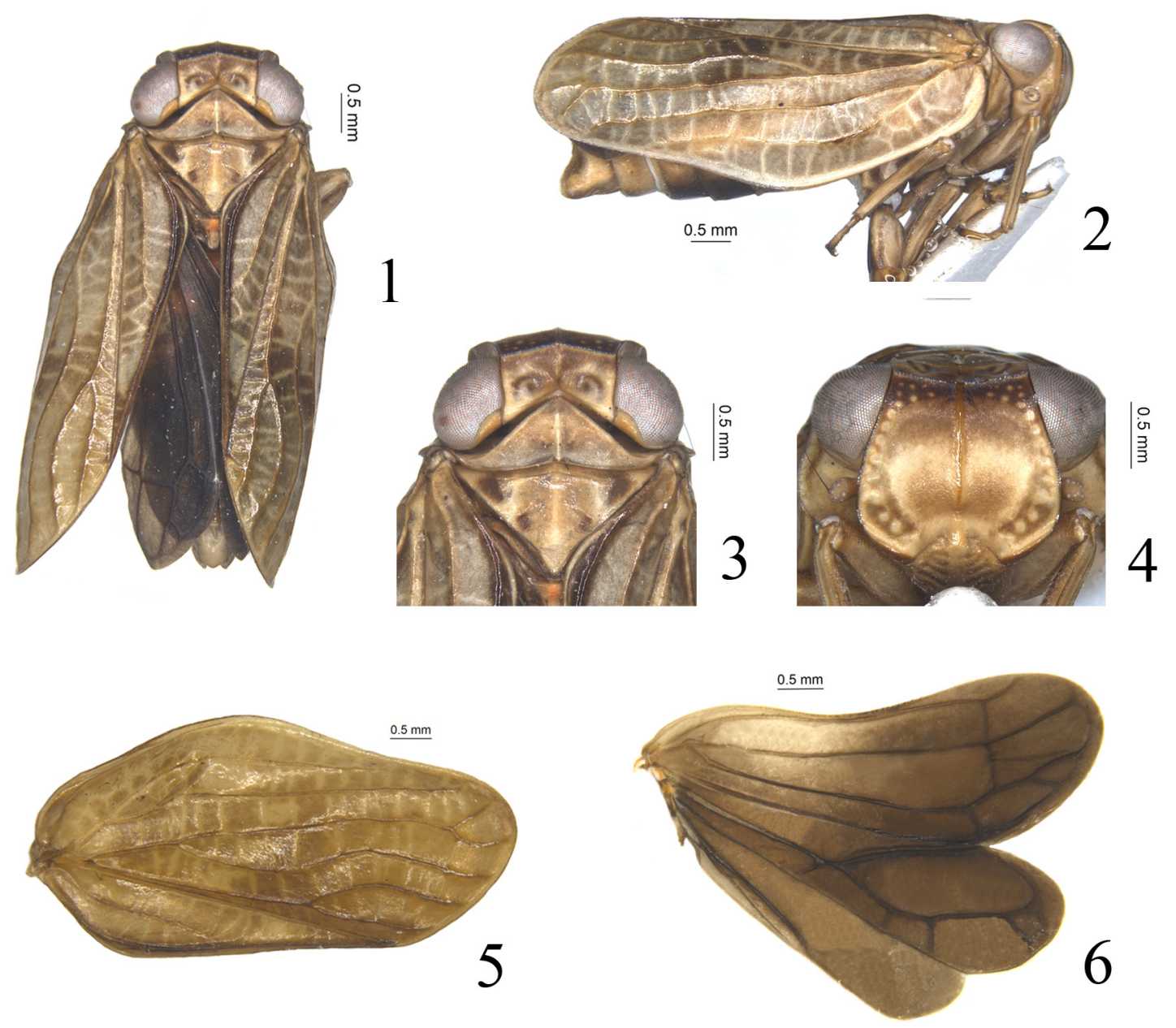

FIGURES 1-6. Kodaianellissus intorqueus sp. nov. 1. Adult, dorsal view; 2. Adult, lateral view; 3. Head and thorax; 4. Frons and clypeus; 5. Forewing; 6. Hindwing.

\section{Kodaianellissus intorqueus sp. nov.}

Diagnosis. This new species is similar to Kodaianella longispina Zhang et Chen, 2010, but differs by: 1) The widest part in anal tube of male in dorsal view located in apical 1/3, but the latter species in the apex; 2) Periandrium with one pair of processes, but the latter species with two pairs of processes; 3) Capitulum of gonostylus long and slender, but the latter species broad and short.

Description. Length: male (including forewings) $(\mathrm{N}=13)$ : $6.6-7.1 \mathrm{~mm}$; female (including forewings) $(\mathrm{N}=8)$ : $6.8-8.3 \mathrm{~mm}$.

Vertex tawny, 2.6 times wider at base than long in midline, with two round brownish markings shaped to circle near base (Figs. 1,3); anterior margin angularly and slightly convex, posterior margin angularly concave, lateral margins parallel (Fig. 3). Frons tawny, 1.3 times broader at widest part than long in midline, 1.5 times broader at widest part than apical margin (Fig. 4); anterior margin black, lateral margins black but tawny near base, median carina tawny (Fig. 4); frons with one very obvious and broad light yellow M-shaped marking near middle, apical part of frons and lateral area with around 16 light yellow tubercles on each side; the base of frons light yellow (Fig. 4). Postclypeus tawny, middle part yellow with several brownish transverse strips on each side (Fig. 4). Compound 
eyes grayish brown, supported by tawny callus (Figs. 1, 3). Gena yellowish brown (Fig. 2). Pronotum tawny, 3.1 times wider at base than length in midline; anterior margin sharply convex, carinate, posterior margin brown, median carina yellow, with two small brown incisions on the disc (Fig. 3). Mesonotum light tawny, 2.0 times wider in anterior margin than long in midline; lateral area with two obvious brownish markings respectively near apex and near base on each side, the apical one larger (Fig. 3). Forewings tawny, 2.0 times wider at longest part than widest part, longitudinal veins dark brown and elevated, transverse veins light yellow (Figs. 1, 5). Hind wings brown (Fig. 6). Legs tawny (Fig. 2). The color described above from specimens taking out from alcohol.

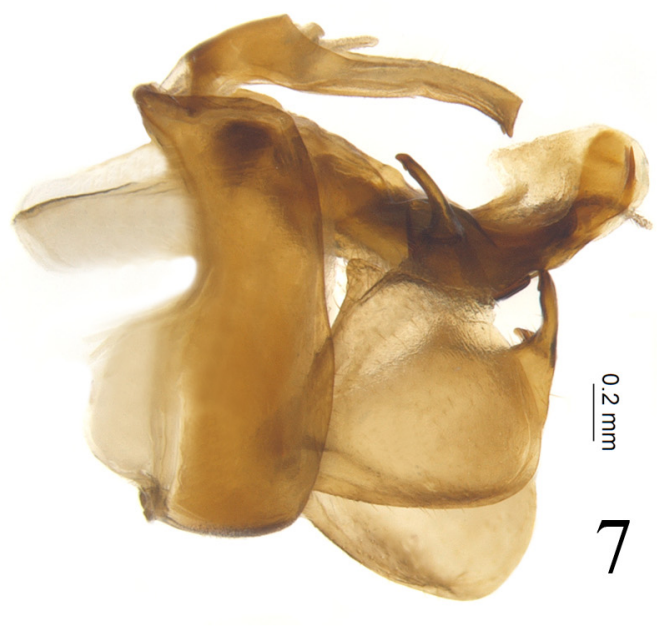

7

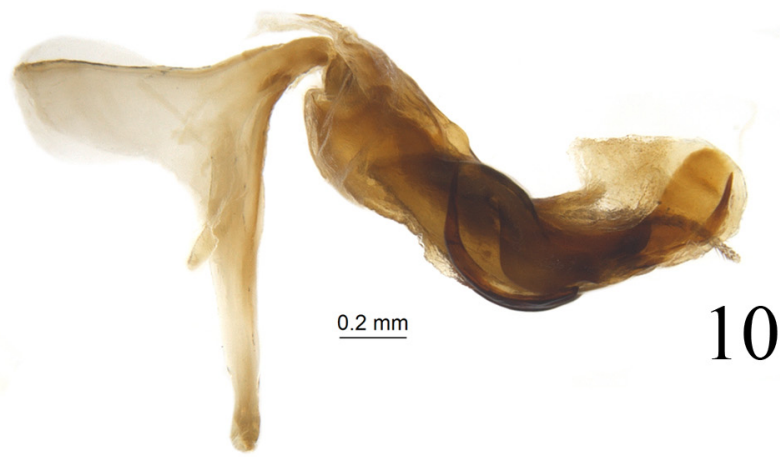

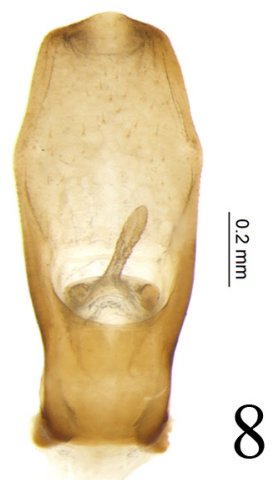

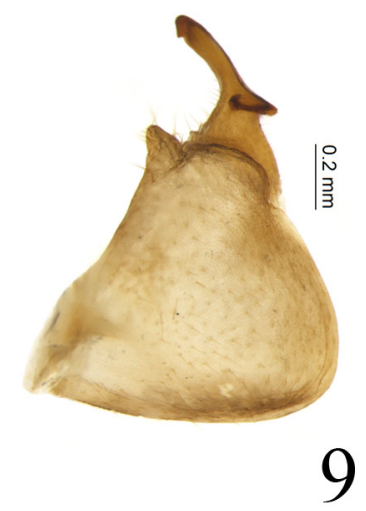

9

FIGURES 7-11. Kodaianellissus intorqueus sp. nov. 7. Male terminalia, lateral view; 8. Male anal tube, dorsal view; 9. Gonostylus, lateral view; 10. Phallic complex, lateral view; 11. Phallic complex, ventral view.

Male terminalia. Anal tube in lateral view extremely long and narrow, dorsal and ventral margins parallel from the anal opening, ventral margin prominent ventrally at apex (Fig. 7); in dorsal view long cylindrical, 2.3 times longer in midline than widest part, widest at apical $1 / 3$, apical margin slightly convex at middle in dorsal view (Fig. 8); apical part concave at middle with two lateral angles convex in postero-dorsal view; epiproct short, located at basal 1/3 of anal tube (Fig. 8). Gonostylus triangular in lateral view, widest at middle, posterior margin sloping posterior, caudo-ventral angle rounded; dorso-lateral margin with large triangular process near the base of capitulum (Figs. 7, 9). Capitulum of gonostylus very long and slender, clavate, directed cephalad; apex and posterior margin of capitulum with auricular processes (Fig. 9). Pygofer in lateral view long and slender, anterior and posterior margins parallel, dorsal margin slightly sloping posterior (Fig. 7). Periandrium in lateral view with both sides elevated and twisting at middle, dorso-lateral lobe slightly membranous in the dorso-apical part, convex to a triangular structure directed cephalad, ventral apical part slightly sclerotized on each side with one sharp spine outside directed dorsad (Fig. 10). Ventral periandrium lobe apparently shorter than dorso-lateral lobe, in ventral view apical margin triangularly convex at middle (Fig. 11). Aedeagus with pair of relatively broad hook-like processes near middle directed dorsad (Fig. 10), this pair of processes in ventral view directed outward (Fig. 11). In ventral view periandrium slightly broader in basal part than apical part (Fig. 11).

Female terminalia. Anal tube in dorsal view long cylindrical, 2.4 times broader in midline than widest part, 
apical margin slightly rounded, lateral margins parallel; anal opening situated at basal $1 / 4$ (Fig. 12). Anterior connective lamina of gonapophysis VIII with three large teeth in apical group, and three keeled teeth in lateral group (Fig. 18). Endogonocoxal process membranous and developed, reaching same level with anterior connective lamina (Fig. 18). Posterior connective lamina of gonapophysis IX in lateral view long and narrow, boat-shaped (Fig. 16), in ventral view triangular, narrowing from base to apical part, apical part concave medially, lateral margins with one triangular process directed outward each side (Fig. 14). Gonoplacs in dorsal view fused near base, widest at base, outer lateral margins oblique (Fig. 13), in lateral view gonoplac subrectangular (Fig. 15). Hind margin of sternite VII slightly concave at middle (Fig. 17).
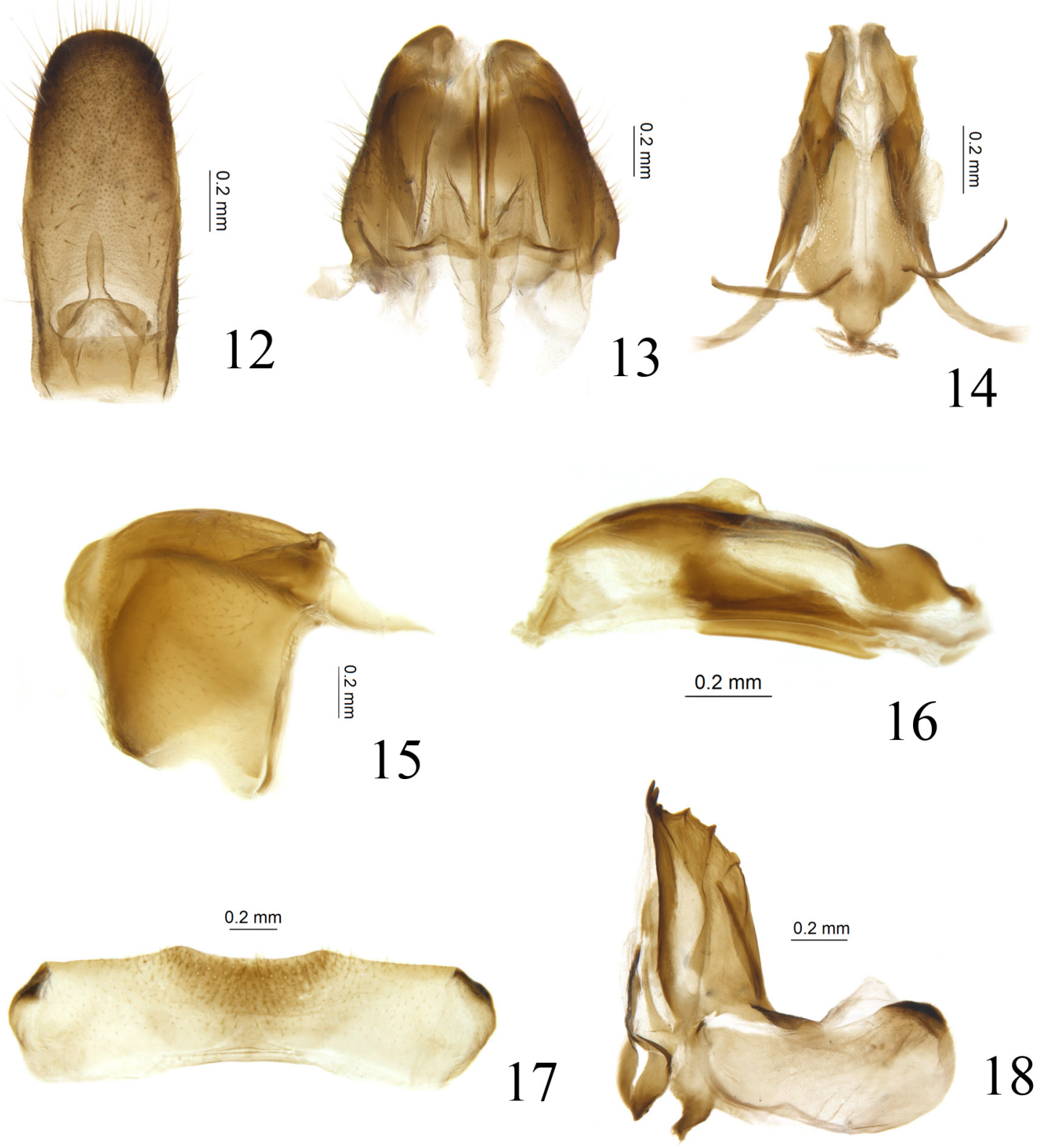

FIGURES 12-18. Kodaianellissus intorqueus sp. nov. 12. Female anal tube, dorsal view; 13. Gonoplac, dorsal view; 14. Gonapophysis IX and gonaspiculum bridge, ventral view; 15. Gonoplac, lateral view; 16. Gonapophysis IX and gonaspiculum bridge, lateral view; 17. Sternite VII; 18. Gonocoxa VIII and gonapophysis VIII, lateral view.

Type materials. Holotype: ${ }^{\lambda}$, China, Yunnan Province, Xishuangbanna, Mengla County, Menglun, N $21^{\circ} 54^{\prime}$ 3.92", E 101 16’ 7.15", 689m, 6 viii 2011, coll. Guo Zheng (IZCAS). Paratypes: $1{ }^{\Uparrow} 1$, , same data as holotype (IZCAS); 2 우, China, Yunnan Province, Xishuangbanna, Mengla County, Menglun, $200 \mathrm{~m}$ eastward along the highway of Lvshilin Natural Reserve, limestone seasonal rainforest, secondary forest, N 21 $54^{\prime} 6.17^{\prime \prime}$, E $101^{\circ} 16^{\prime}$ 8.43”, 738m, 8 viii 2011, coll. Guo Zheng (IZCAS); $1 \overbrace{}^{\Uparrow} 1$, , China, Yunnan Province, Xishuangbanna, Mengla 


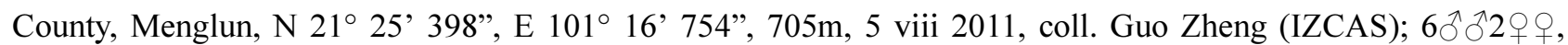
China, Yunnan Province, Xishuangbanna, Mengla County, Menglun, N 215 54' 7.69”, E 101¹6' 9.59”, 599m, 9 viii 2011, coll. Guo Zheng (IZCAS); $3 \delta^{\lambda} 2$ 우으, China, Yunnan Province, Xishuangbanna, Mengla County,

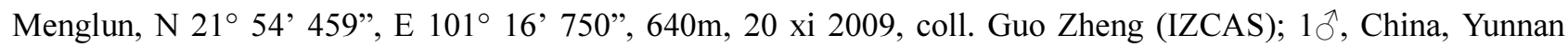
Province, Xishuangbanna, Mengla County, Menglun, Nanshahe, Jiyulin, N 21 $36^{\prime} 12.1^{\prime \prime}$, E $101^{\circ} 34^{\prime} 23.9^{\prime \prime}, 826 \mathrm{~m}$, 14 vii 2012, coll. Guo Zheng (IZCAS).

Etymology. The Latin name "intorqueus" means twisted, referring to the twisted special structure on the dorsal margin of periandrium.

\section{Tetricissus gen. nov.}

Type species: Tetrica philo Fennah, 1978; here designated.

Diagnosis. Tetricissus gen. nov. is superficially similar to the genus Tetrica Stål, 1866 in which the type species $T$. philo Fennah, 1978 was previously described. In addition to the hindwing characters that separate Sarimini (for Tetrica) from Kodaianellini to which Tetricissus belongs, it differs from Tetrica by: 1) The lateral margins of frons slightly and roundly enlarged below the compound eyes, but in Tetrica, angularly expanded, the angles being much larger; 2) Forewing with MP vein first separate at basal 1/4, but in Tetrica, the first fork of MP near middle; 3) Clypeus flattened, without carina, in contrast, Tetrica with elevated carina from apex to base.

Description. Head with compound eyes almost as wide as thorax (Fig. 19). Vertex nearly rectangular, obviously broader than long, without median carina, anterior, lateral and posterior margins carinate and elevated; anterior margin truncated, lateral margins slightly inclined inward from top to bottom, posterior margin angularly concave at middle (Fig. 19). Frons roundly widened below antenna, apical margin slightly concave at middle, apical and lateral margins carinate and elevated, median carina elevated from apex extending to near base of frons; frons with apical and lateral areas distributed with numerous inconspicuous tubercles (Fig. 21). Frontoclypeal suture dorsally convex (Fig. 21). Clypeus flattened, without carina (Fig. 21). Rostrum short, reaching midcoxae. Gena in lateral view flattened and oblique, with small protuberance near base (Fig. 20). Pronotum triangular, anterior and posterior margins elevated, anterior margin sharply convex, reaching middle level of compound eyes, without median carina (Fig. 19). Mesonotum smooth, without carina (Fig. 19). Forewings elongate, distinctly longer than width (Fig. 20), with broad hypocostal plate (Fig. 21); forewing broadened at basal 1/3 of costal margin, longitudinal veins obvious and elevated (Fig. 19). Vein ScP+R first separate at basal 1/5, ScP+RA extremely long and sinuate, reaching the apical 1/5 of costal margin, the terminal of RP vein reaching the outer margin of forewing; MP vein first fork near the basal $1 / 4, \mathrm{MP}_{1+2}$ straight, fork again at apical 1/5, $\mathrm{MP}_{3+4}$ sinuate, without fork; $\mathrm{CuA}$ vein first separates at apical 1/3; the fork of ScP+R vein placed before MP vein, CuA vein last (Fig. 20). Clavus obvious and long, veins Pcu and $\mathrm{A}_{1}$ fused at middle of clavus, the end of clavus reaching the outer margin of forewing, ScP+RA vein reach the same level (Figs. 19, 20); forewing with numerous transverse veins, but not distinct (Figs. 19, 20). Hindwing developed, 3-lobed, longitudinal veins well developed, ScP-R-MP-CuA lobe distinctly wider than $\mathrm{A}_{1}$-Pcu lobe; $\mathrm{A}_{2}$ lobe as wide as $\mathrm{A}_{1}$-Pcu lobe, slightly shorter (Fig. 23). Hind tibia with 2 lateral spines on apical half.

Etymology. The name is an arbitrary combination between two generic names of issids: Tetrica and Issus, indicating that this genus is established on one species from the genus Tetrica, and "Issus" is the type genus name of this family. The gender is masculine.

Note. This genus refers to the taxon "Tetrica" philo on the molecular phylogeny trees (Wang et al., 2016). Photos of the holotype of Tetrica fusca Stål, 1870, type species of Tetrica, are available in Gnezdilov et al. (2015: 90, figs 20-23) for better comparison of the Vietnamese species Tetricissus philo (Fennah, 1978).

\section{Tetricissus philo (Fennah, 1978) n. comb.}

Tetrica philo Fennah, 1978: 269.

Redescription. Length: male (including forewings) $(\mathrm{N}=2)$ : $6.7-9.0 \mathrm{~mm}$; female (including forewings) $(\mathrm{N}=2)$ : 9.1 $\mathrm{mm}$. 

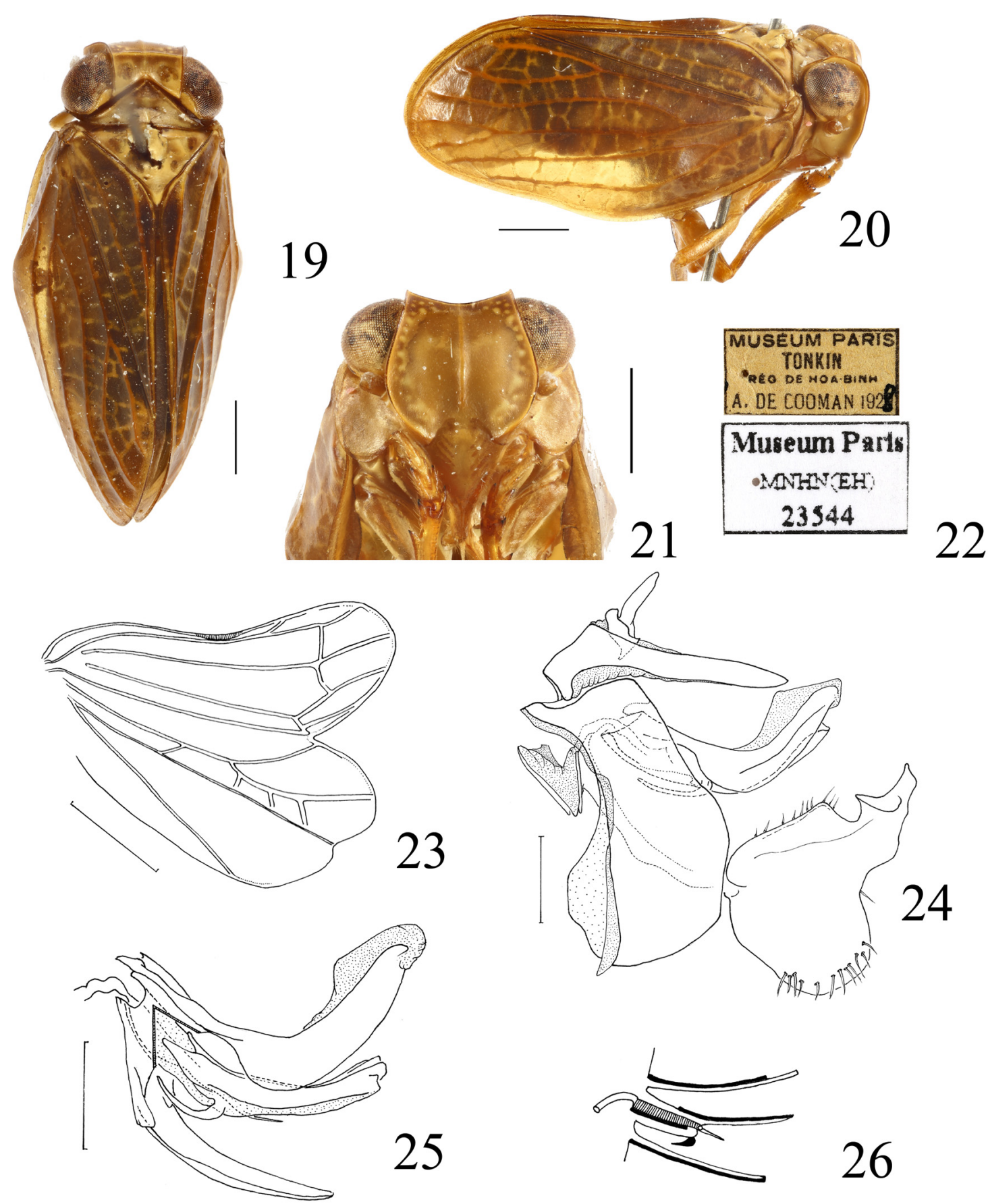

FIGURES 19-26. Tetricissus philo (Fennah, 1978) n. comb. 19. Adult, dorsal view; 20. Adult, lateral view; 21. Frons and clypeus; 22. Labels; 23. Hindwing; 24. Male terminalia, lateral view; 25. Phallic complex, lateral view; 26. Schemata of phallic complex. Scale bars 19-21, $23=1 \mathrm{~mm}, 24-25=0.5 \mathrm{~mm}$.

Vertex tawny, 3.2 times wider at base than long in midline; anterior, lateral and posterior margins all elevated and brown (Fig. 19). Frons tawny, 1.1 times broader at widest part than long in midline, 1.4 times broader at widest part than apical margin; anterior and lateral margins carinated and dark brown, median carina tawny; apical part of frons and lateral areas with around 15 light yellow tubercles on each side becoming larger from apex to lateral area (Fig. 21). Postclypeus tawny (Fig. 21). Compound eyes dark tawny, supported by tawny callus (Fig. 19). Gena yellowish brown (Fig. 20). Pronotum tawny, 3.1 times wider at base than length in midline; anterior and posterior margins carinated and brown, posterior margins carinated and brown (Fig. 19). Mesonotum tawny, 1.8 times wider at anterior margin than long in midline (Fig. 19). Forewings tawny, 2.2 times wider at longest part than widest part, 
costal margin widest at basal $1 / 3$ in lateral view, anterior and posterior margins almost parallel, longitudinal veins dark brown and elevated (Figs. 19, 20). Hind wings grayish brown. Legs tawny.

Male terminalia. Anal tube in lateral view extremely long and narrow; epiproct short, located at basal 1/3 of anal tube (Fig. 24). Gonostylus triangular in lateral view, widest at middle, dorso-lateral margin elevated in apical part, caudo-ventral angle rounded (Fig. 24). Capitulum of gonostylus with teeth on the apex and the antero-lateral part (Fig. 24). Pygofer in lateral view long and slender, anterior and posterior margins nearly parallel, dorsal margin slightly sloping to posterior (Fig. 24). Periandrium in lateral view with dorsal lobe slightly membranous in the dorso-apical part; pair of lateral lobes shorter than dorsal lobe, aedeagus with pair of short hook-like processes derived from its basal 1/4 directed to near base; ventral periandrium lobe little shorter than lateral lobe (Figs. 25, 26).

Materials examined. $2 \hat{\jmath} 1$ 우, Vietnam, Tonkin, reg. De Hoa-Binh, 1928, A. De Cooman (MNHN); 1 , Vietnam, Tonkin, Hoa-Binh, 1919, J. De. Cooman, R. Oberthur (MNHN).

\section{Issidae Spinola, 1839}

\section{Hemisphaeriinae Melichar, 1906}

\section{Sarimini Wang, Zhang et Bourgoin, 2016}

\section{Longieusarima gen. nov.}

Type species: Longieusarima lunulia $\mathbf{s p . ~ n o v . , ~ h e r e ~ d e s i g n a t e d . ~}$

Diagnosis. Longieusarima gen. nov. looks similar to Eusarima Yang, 1994, but differs by: 1) Vertex nearly as wide as long (Fig. 29), while more wider than long in Eusarima (Chan \& Yang, 1994: fig. 45a); 2) The first fork of MP vein occurs well before the fork of CuA vein on forewing (Fig. 31), while in Eusarima, almost in the same level (Chan \& Yang, 1994: fig. 45c); 3) both median carina and sublateral carinae of frons only visible at basal half (Fig. 30), while both are very clear from base to apex in Eusarima (Chan \& Yang, 1994: fig. 45b). This genus is also very similar to Parasarima Yang, 1994, from which it differs by: 1) ScP+RA vein of forewing obvious shorter than Parasarima; 2) The ratio of length and width of vertex is 1.0 in this genus (Fig. 29) but less than 0.5 in Parasarima (Chan \& Yang, 1994: fig. 39a); 3) MP vein on forewing forks first before CuA vein (Fig. 31), while at the same level in Parasarima (Chan \& Yang, 1994: fig. 39c).

This genus is also close to Sinesarima Yang, 1994 and Neosarima Yang, 1994, but the longer ScP+RA forewing branch and the longer median and sublateral carinae of frons in Longieusarima allow it to be separated from these two genera.

Description. Head with compound eyes very slightly wider than thorax (Figs. 27, 29). Vertex nearly quadrate, as long as wide, median carina absent; anterior margin obviously and angularly convex, posterior margin roundly concave at middle (Figs. 27, 29). Frons angularly expanded outwardly below antenna; apical margin slightly angularly convex; sublateral carinae obviously elevated at apical half, reaching middle level of compound eyes; median carina present but weak, extending to near middle of frons (Fig. 30). Frontoclypeal suture dorsally convex (Fig. 30). Clypeus flattened, without carina (Fig. 30). Rostrum short, reaching mesocoxae. Gena in lateral view flattened and oblique, vertex and frons meeting at acute angle (Fig. 28). Pronotum triangular, anterior and posterior margins elevated, median area with two small incisions, without median carina (Figs. 27, 29). Mesonotum with weak median carina present in basal half (Figs. 27, 29). Forewings elongate, apparently longer than width, hypocostal plate present; forewing expanded outwardly at basal third, longitudinal veins obvious and elevated (Figs. 27, 28, 31); vein $\mathrm{ScP}+\mathrm{R}$ first separating near base, $\mathrm{ScP}+\mathrm{RA}$ short, reaching middle of costal margin, the terminal of RP vein reaching the outer margin of forewing; MP vein first fork at basal third, $\mathrm{MP}_{1+2}$ fork again at apical 1/5, $\mathrm{MP}_{3+4}$ simple, not forking again; CuA vein first bifurcate at middle; MP first fork before CuA (Figs. 27, 28, 31); clavus obvious, veins Pcu and $A_{1}$ fused near middle, transverse veins of forewing well developed (Figs. 27, 31). Hindwing well developed, 3-lobed, Pcu- $\mathrm{A}_{1}$ lobe as wide as ScP-R-MP-Cu lobe, anal lobe broad; Pcu single, Pcu and $A_{1}$ anastomosing for long distance; $A_{2}$ non branched (Fig. 32). Hind tibia with 2 lateral spines on apical half. 
Male terminalia. Anal tube long (Figs. 33, 38). Gonostylus triangular in profile, broadening from base to apex, widest at apical 1/3, caudo-ventral angle rounded, capitulum finger-shaped (Figs. 33, 35, 38). Pygofer with dorsal margin apparently narrower than ventral margin, posterior margin obviously and caudally produced (Figs. 33,38 ). Periandrium shallowly U-shaped, Aedeagus with pair of ventral processes derived from apical $1 / 9$ and directed basad (Figs. 36, 38). Apical part of periandrium divided into dorsal lobe, pair of lateral lobes and ventral lobe.

Female terminalia. Anal tube relatively short in lateral view. Anterior connective lamina of gonapophysis VIII with teeth at apex, outer lateral margin and inner lateral margin without teeth (Fig. 47). Gonocoxa VIII subquadrangular, oblique connected with gonapophysis VIII (Fig. 47). Posterior connective lamina of gonapophysis IX with large special structure the top of which is rough on surface (Figs. 43, 45). Gonoplac rounded in lateral view (Fig. 44), fused at middle, widest at basal half (Fig. 42). Hind margin of sternite VII almost straight at middle (Fig. 46).

Etymology. The name is a combination of Latin prefix "longi-" and the genus name Eusarima, indicating this genus with vertex obviously protruded forward in the Eusarima group. The gender is feminine.

Note. This genus refers to the taxon "gen. nov. apud Eusarima" on the molecular phylogenic analyses (Wang et al., 2016).
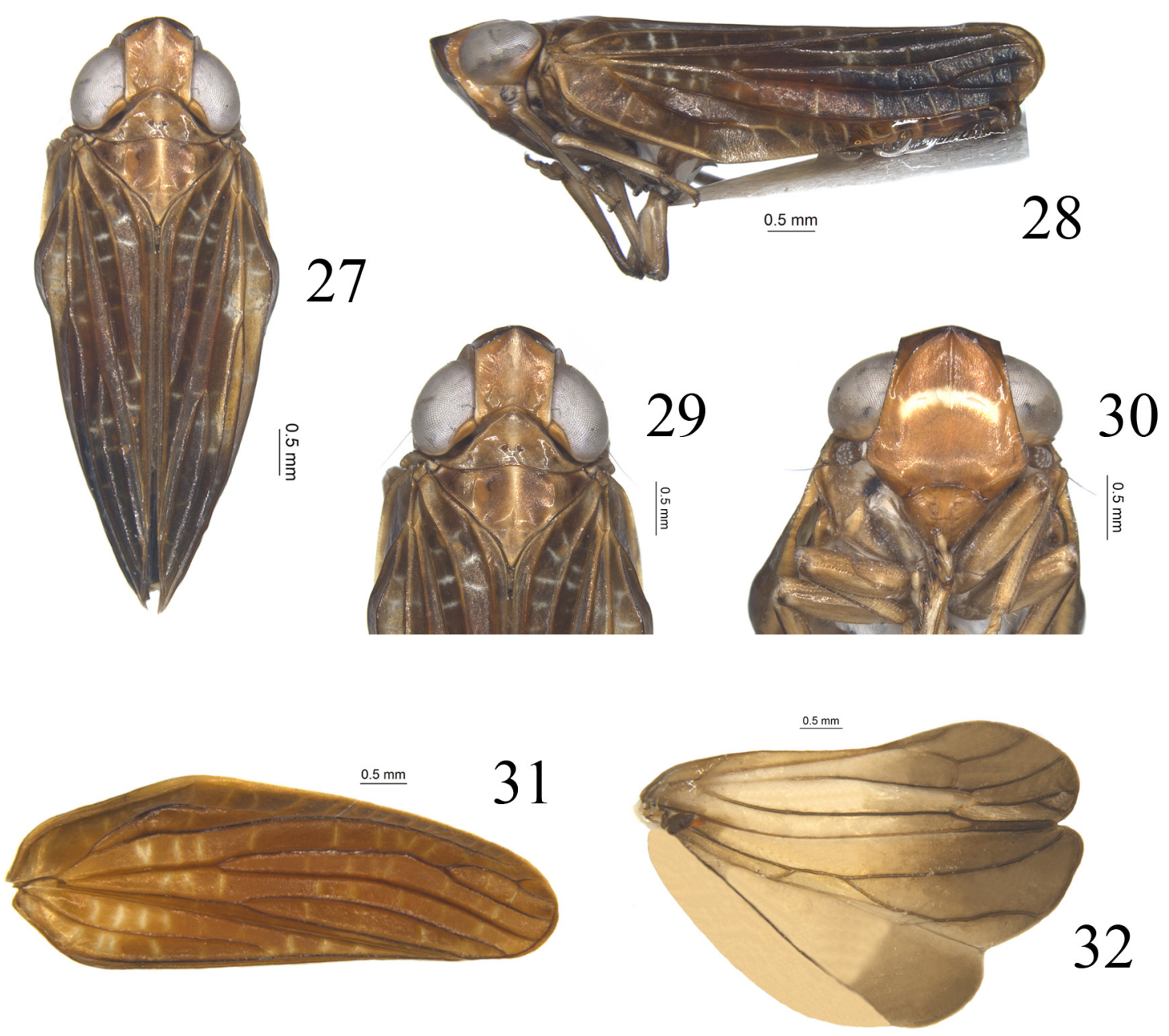

FIGURES 27-32. Longieusarima lunulia sp. nov. 27. Adult, dorsal view; 28. Adult, lateral view; 29. Head and thorax; 30. Frons and clypeus; 31 . Forewing; 32. Hindwing.

\section{Longieusarima lunulia sp. nov.}

Diagnosis. This new species can be identified by these particular characters in Sarimini: 1) Vertex 1.0 times wider 
at base than long in midline (Fig. 29); 2) Lateral angles of frons angularly expanded outwardly, median area with one light yellow curved transverse marking on the disc (Fig. 30); 3) Forewing with ScP+RA vein extending to the middle of forewing, the first fork of MP vein distinctly separate before CuA vein (Fig. 28).

Description. Length: male (including forewings) $(\mathrm{N}=5): 6.3-7.0 \mathrm{~mm}$; female (including forewings) $(\mathrm{N}=1): 7.3$ $\mathrm{mm}$.

Vertex tawny, 1.0 times wider at base than long in midline, apical half light yellow in midline; anterior margin carinated and black; lateral margins carinated with apical half brown, basal half white; posterior margin elevated and white (Figs. 27, 29). Frons tawny, 1.0 times longer in midline than widest part, 1.6 times broader at widest part than apical margin; anterior and lateral margins carinated and brown, sublateral carinae brown, median carina tawny; median part with one broad light yellow meniscus shaped transverse band (Fig. 30). Frontoclypeal sulcus brown (Fig. 30). Postclypeus tawny (Fig. 30). Compound eyes grayish white, supported by tawny callus (Fig. 29). Gena brown, in lateral view with one yellow oblique transverse band (Fig. 28). Pronotum tawny, 2.5 times wider at base than length in midline, anterior and posterior margins carinate and brown (Figs. 27, 29). Mesonotum tawny, anterior margin 1.5 times wider than long in midline, apical half of midline light yellow (Figs. 27, 29). Forewings tawny, 2.8 times wider at longest part than widest part, longitudinal veins reddish brown, with several light yellow transverse veins (Figs. 28, 31). Hind wings grayish brown (Fig. 32). Legs tawny (Fig. 30). The color described above from specimens taking out from alcohol.
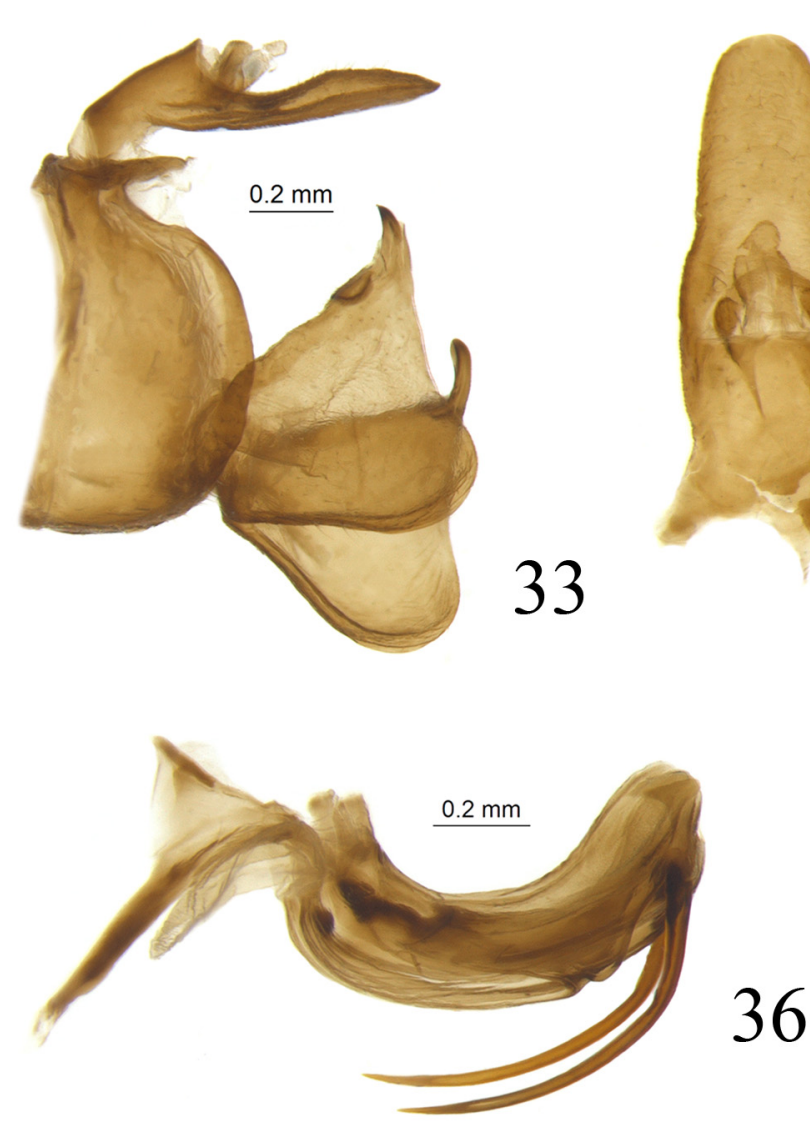
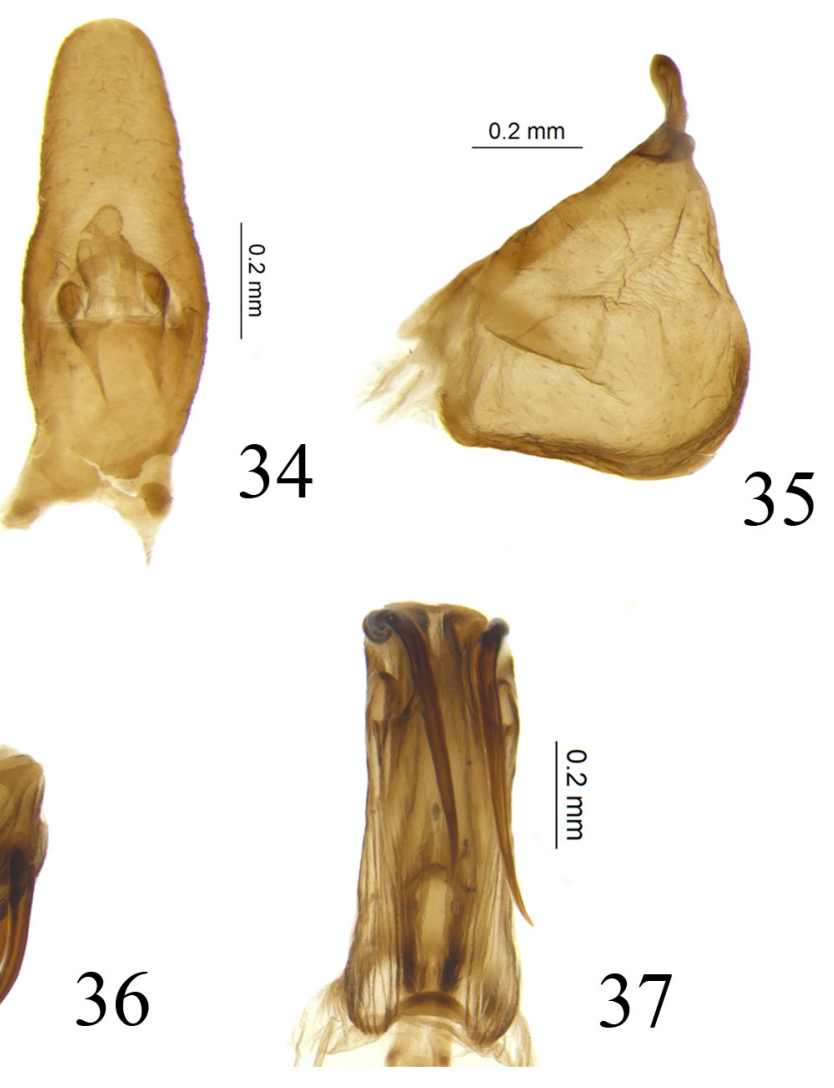

FIGURES 33-37. Longieusarima lunulia sp. nov. 33. Male terminalia, lateral view; 34. Male anal tube, dorsal view; 35. Gonostylus, lateral view; 36. Phallic complex, lateral view; 37. Phallic complex, ventral view.

Male terminalia. Anal tube in lateral view long and slender, reaching the posterior margin of gonostyli, dorsal margin of anal tube curved downward near middle, ventral margin almost straight (Figs. 33, 38); in dorsal view long cylindrical, widest at basal 1/3, 2.6 times longer in midline than widest part, apical margin rounded, lateral margins almost parallel in apical half; epiproct short, located at basal $1 / 3$ of anal tube (Fig. 34). Gonostylus triangular in lateral view, widest at apical $1 / 3$, dorsal and posterior margins nearly straight, caudo-ventral angle rounded, the apex of dorsal margin near to base of capitulum with auriform structure (Figs. 35, 38). Capitulum of gonostylus finger-shaped, directed to apex (Fig. 35). Pygofer in lateral view large and broad, apical part much 
narrower than basal part, 2.0 times wider in ventral margin than dorsal margin, posterior margin gradually broadened from apex to apical 1/6, then apparently caudad convex (Figs. 33, 38). Periandrium in lateral view with dorsal and ventral margins almost parallel,. Aedeagus with pair of long acute processes under the ventral margin directed cephalad, derived from apical $1 / 9$ ventrally reaching basal 1/3 of periandrium (Figs. 36, 38), directed outward in ventral view (Fig. 37). Periandrium with apical part rounded, divided into dorsal lobe, pair of lateral lobes and ventral lobe of approximately equal length fused together, dorsal lobe with triangular processes directed dorsad apically (Figs. 36, 38).

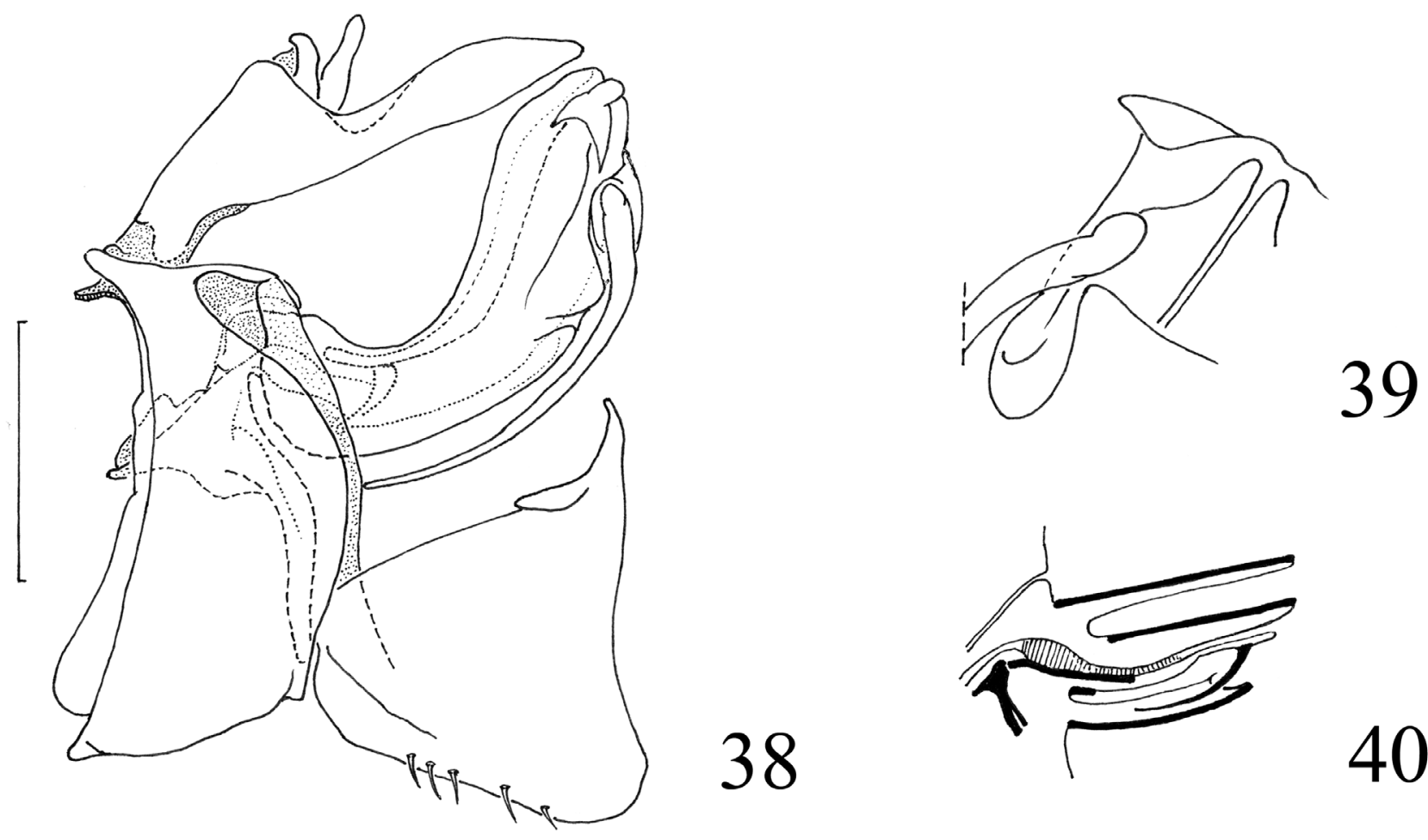

FIGURES 38-40. Longieusarima lunulia sp. nov. 38. Male terminalia, lateral view; 39. Apical part of phallic complex, ventral view; 40. Schemata of phallic complex. Scale bars $=0.5 \mathrm{~mm}$.

Female terminalia. Anal tube in dorsal view long cylindrical, 1.9 times broader in midline than widest part, apical margin rounded, lateral margins almost parallel at apical $2 / 3$, basal $1 / 3$ expanded outwardly, anal opening situated at base (Fig. 41). Anterior connective lamina of gonapophysis VIII with one tooth at apex, outer lateral margin and inner lateral margin without teeth (Fig. 47). Endogonocoxal process membranous and developed, reaching the same level with anterior connective lamina, obvious and angular expanded near base (Fig. 47). Posterior connective lamina of gonapophysis IX in lateral view triangular, narrowing from base to apex, carries a large triangular structure on its top (Fig. 45), triangular structure in ventral view with apical margin concave at middle, rough at middle, posterior connective lamina of gonapophysis IX in ventral view with small spinous process directed outward at apical 1/3 (Fig. 43). Gonospiculum bridge rectangular (Fig. 45). Gonoplac rounded in lateral view (Fig. 44), in dorsal view widest at basal half, fused at middle near base (Fig. 42). Hind margin of sternite VII almost straight at middle (Fig. 46).

Type materials. Holotype: ${ }^{\top}$, China, Hainan, Jianfengling, Chahekou, N 18 ${ }^{\circ} 44.727^{\prime}$, E $108^{\circ} 59.632^{\prime}, 235$ m, 17 viii 2010, coll. Guo Zheng (IZCAS). Paratypes: $40^{\lambda} \hat{1} 1$, the same data as holotype (IZCAS).

Etymology. Latin word "lunulia", means falcate, referring to the yellowish falcate transverse marking on the middle of frons. 


\section{Discussion}

Combining morphological and molecular characteristics together in the study of the taxonomic composition of the Issidae (Wang et al., 2016) has proven to be very effective, providing for the first time a phylogeny-driven classification of the family. However only a small part of the Oriental issid material was included in the study. It is expected that in the short future several other genera will be discovered in the already available material in collections, which moreover represents very probably only a small fraction of real diversity the family.
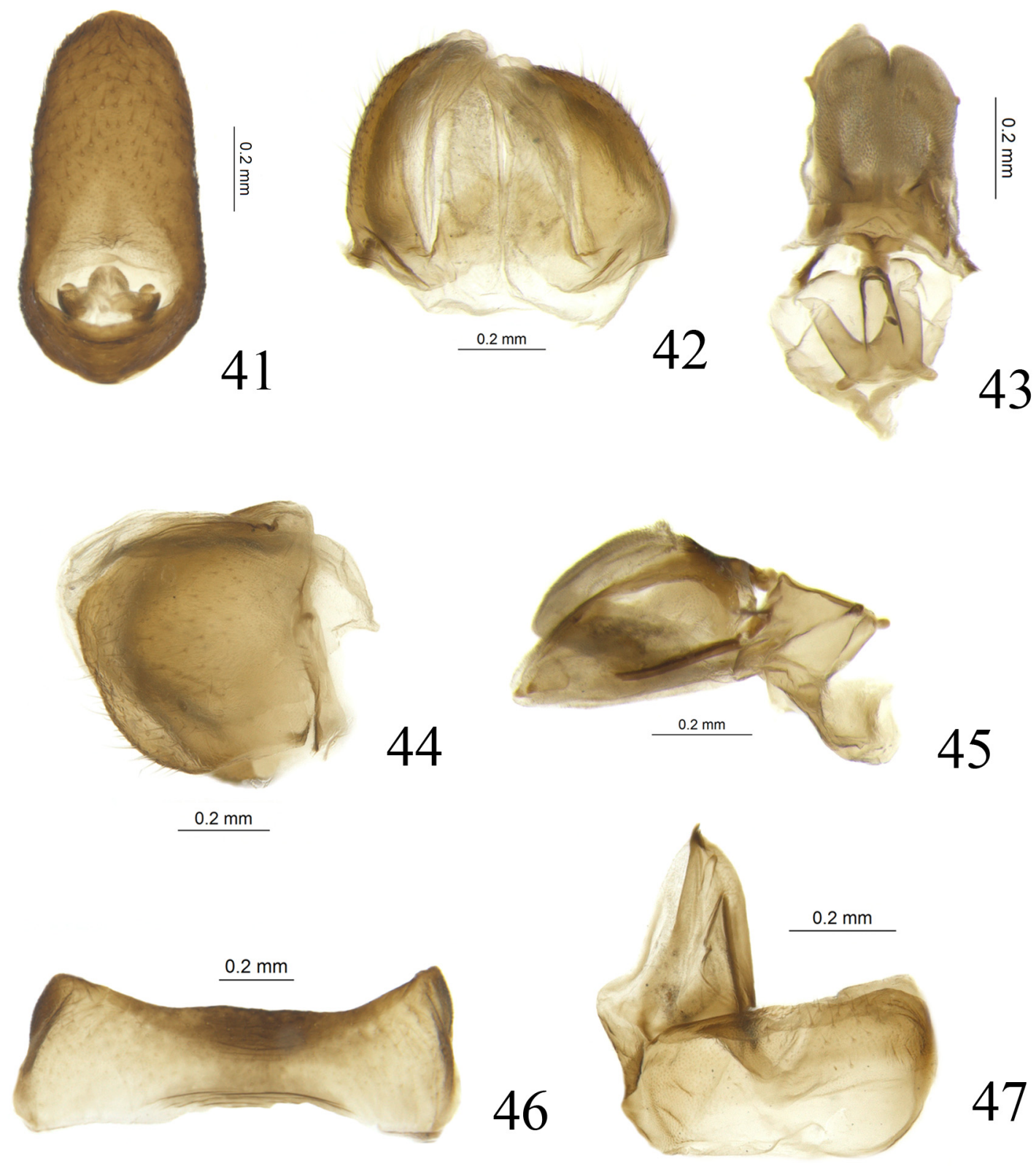

FIGURES 41-47. Longieusarima lunulia sp. nov. 41. Female anal tube, dorsal view; 42. Gonoplac, dorsal view; 43. Gonapophysis IX and gonaspiculum bridge, ventral view; 44. Gonoplac, lateral view; 45. Gonapophysis IX and gonaspiculum bridge, lateral view; 46. Sternite VII; 47. Gonocoxa VIII and gonapophysis VIII, lateral view.

\section{Acknowledgements}

The authors sincerely thank Pr. Li Shuqiang (Institute of Zoology, Chinese Academy of Sciences, Beijing, China) for loan of specimens and Mr. Laurent Fauvre (Muséum national d'Histoire naturelle, Paris, France) for taking pictures of some specimens. We are extremely grateful to Prof. John Richard Schrock (Emporia State University, 
USA) for reviewing the manuscript. This study was supported by the National Natural Science Foundation of China $(31420103911,31372234)$, the Ministry of Science and Technology of the People's Republic of China (2005DKA21402, 2015FY210300) and the China Scholarship Council.

\section{References}

Bourgoin, T. (1987) A new interpretation of the homologies of the Hemiptera male genitalia, illustrated by the Tettigometridae (Hemiptera, Fulgoromorpha). Proceedings of the 6th Auchenorrhyncha Meeting, 1987, 113-120. [Turin, Italy, 7-11 September]

Bourgoin, T. (1993) Female genitalia in Hemiptera Fulgoromorpha, morphological and phylogenetic data. Annales de la Société Entomolologique de France, 29 (3), 225-244.

Bourgoin, T. (2017) FLOW (Fulgoromorpha Lists On the Web): a world knowledge base dedicated to Fulgoromorpha. Version 8, updated 30 July 2017. Available from: http://hemiptera-databases.org/flow/ (accessed 30 July 2017)

Bourgoin, T., Wang, R.R., Asche, M., Hoch, H., Soulier-Perkins, A., Stroiński, A., Yap, S. \& Szwedo, J. (2015) From micropterism to hyperpterism: recognition strategy and standardized homology-driven terminology of the forewing venation patterns in planthoppers (Hemiptera: Fulgoromorpha). Zoomorphology, 134 (1), 63-77. https://doi.org/10.1007/s00435-014-0243-6

Chan, M.L. \& Yang, C.T. (1994) Issidae of Taiwan (Homoptera: Fulgoroidea). Chen Chung Book, Taichung, 168 pp.

Fennah, R.G. (1978) Fulgoroidea (Homoptera) from Vietnam. Annales Zoologici, 34 (9), 207-279.

Gnezdilov, V.M. (2013) On the genera Sivaloka Distant, 1906 and Kodaianella Fennah, 1956 (Hemiptera: Fulgoroidea: Issidae). Deutsche Entomologische Zeitschrift, 60 (1), 41-44.

Gnezdilov, V.M., Le Cesne, M., Soulier-Perkins, A. \& Bourgoin, T. (2015) New Guinean Issidae: description of new taxa in a poorly known island fauna (Hemiptera, Fulgoroidea). Zootaxa, 3904 (1), 82-94. https://doi.org/10.11646/zootaxa.3904.1.4

Wang, M.L., Zhang, Y.L. \& Bourgoin, T. (2016) Planthopper family Issidae (Insecta: Hemiptera: Fulgoromorpha): linking molecular phylogeny with classification. Molecular Phylogenetics and Evolution, 105, 224-234. https://doi.org/10.1016/j.ympev.2016.08.012 